\title{
Fecal Excretion of Bile Acids: a New Technique for Studying Bile Acid Kinetics
}

\section{in Patients with Ileal Resection}

\author{
James F. Woodbury and Fred Kern, Jr. \\ From the Division of Gastroenterology, Department of Medicine, University of \\ Colorado School of Medicine, Denver, Colorado 80220
}

A в S T R A C T The fecal elimination and enterohepatic circulation of bile acid was studied in 11 patients, 10 patients with varying degrees of ileal disease or resection and 1 patient with pancreatic insufficiency and no ileal disease. A new technique was employed which involved the nearly simultaneous administration of cholic acid- ${ }^{14} \mathrm{C}$ and a nonabsorbable marker, ${ }^{51} \mathrm{CrCl}_{3}$. Each individual stool specimen was collected for 36-96 $\mathrm{hr}$ and analyzed separately. Assay of the radioactivity of each isotope allowed the accurate determination of an excretion rate for both cholic acid and ${ }^{51} \mathrm{Cr}$. The difference between these rates was used to calculate an absorption coefficient for cholic acid. In addition, bile acid concentration measured by the steroid dehydrogenase technique, and the water content of each stool was determined.

The patients were divided into groups depending upon how much small intestine was resected or diseased: six patients with less than $100 \mathrm{~cm}$ of ileal resection or disease (group A), and five patients with more than $100 \mathrm{~cm}$ of ileal disease or resection (group B). The ${ }^{51} \mathrm{Cr}$ excretion rate was sinilar in the two groups, but cholic acid $-{ }^{14} \mathrm{C}$ excretion rates were significantly more rapid in group B than in group A. The cholic acid absorption coefficient was essentially normal in the patient with pancreatic insufficiency, moderately decreased in group A patients, and extremely low or zero in group B patients. It was inversely related to the length of intestine diseased or resected.

Daily fecal bile acid excretion was normal to twice normal in group A patients and 2-8 times normal in

Presented in part at the American Gastroenterology Association Meeting, May 1970: 1970. Gastroenterology. 58: 1009. (Abstr.)

Dr. Woodbury was the recipient of a Special Fellowship award of the National Institutes of Health, 5 FO3 AM43256.

Received for publication 12 March 1971 and in revised form 21 June 1971. group B patients. In all patients with ileal disease or resection, there was a direct correlation between fecal bile acid, fecal mass, and fecal water. Each millimole of additional bile acid in the stool was associated with an increase in stool water of 11 moles $(P<0.01)$.

These studies show that the kinetics of bile acids in the enterohepatic circulation can be accurately studied in patients with extensive ileal resection. The regular relationship between fecal bile acid and fecal mass and water suggests, but does not prove, a critical role of bile acid in determining stool water.

\section{INTRODUCTION}

Inflammatory disease of the ileum and surgical resection or bypass of the ileum are often accompanied by diarrhea and steatorrhea. A number of factors are probably involved in the pathogenesis of these symptoms, but the precise role of each has not been entirely clarified. These factors include diminished intestinal absorptive surface, rapid transit through the intestinal tract, population of the upper small intestine by colonic bacteria, and altered bile salt metabolism. Bile salts, which are normally absorbed by the ileum, can cause diarrhea when their concentration in the colon is excessive $(1,2)$. Patients with ileal disorders rapidly excrete a tracer dose of radioactive bile salt (3-6), but the role of bile acid in the production of symptoms is not always clear. Hofmann and Poley found that these patients can be divided into two groups, depending upon the extent of ileal resection (7). Those with resection of less than $100 \mathrm{~cm}$ of terminal ileum had watery diarrhea without much steatorrhea, whereas those with resections of more than $100 \mathrm{~cm}$ had diarrhea and steatorrhea. They postulated that the steatorrhea in the second group was probably caused, at least in part, by reduced jejunal bile salt concentration and decreased micellar solubilization of lipids (8). They 
assumed that in the first group, those with a small resection, hepatic synthesis of bile acid was sufficient to compensate for fecal excretion of bile acid and to maintain adequate jejunal bile acid concentration.

In the normal individual, in the steady state, a constant amount $(2.5-5.0 \mathrm{~g})$ of bile acid is present in the enterohepatic circulation; it undergoes six to 8 complete cycles each day (9). Usually $300-600 \mathrm{mg}$ is excreted in the feces, and a similar amount is synthesized by the liver. When intestinal absorption of bile salts is diminished and bile salts are excreted rapidly in the feces, there is more or less continuous stimulation of hepatic bile acid synthesis. Under these circumstances, the bile acid "pool" in the enterohepatic circulation is not constant throughout the day. Since the usually employed technique for calculation of bile acid kinetics and rates of synthesis is dependent upon the assumption that the pool size in the enterohepatic circulation is constant, this technique cannot be employed in patients with ileal resection or disease. We report here a new technique which permits accurate determination of the fecal excretion rate and the fractional absorption of bile acid in patients with ileal resection and other kinds of diarrhea. The studies show that bile acid absorption correlates well with the extent of intestinal disease or resection. The rate of intestinal transit of a nonabsorbable marker correlated less well with the extent of resection. We also measured the mass of fecal bile acid, fecal mass, and fecal water. The findings support the hypothesis that excess fecal bile acid may play an important role in the diarrhea in all patients with ileal resection. In patients with resection of the entire ileum and no enterohepatic circulation of cholic acid, the maximum daily synthetic rate of bile acid was as much as 8 times the normal rate.

\section{METHODS}

\section{Patients}

11 patients with diarrhea were studied. They were divided into two groups. Group A consisted of five patients in whom less than $100 \mathrm{~cm}$ of ileum had been resected or involved by disease. A patient who had pancreatic insufficiency without intestinal disease was included in this group for convenience. Group B consisted of five patients in whom more than $100 \mathrm{~cm}$ of small intestine had been resected or involved by disease (Table I). The length of intestine resected or diseased as estimated from small intestinal X-rays, operative reports, and surgical pathology reports, was calculated from the ileocecal valve proximally. We assumed an over-all jejunoileal length of $300 \mathrm{~cm}$ (10). All patients were clinically stable before and during

TABLE I

Clinical Features, Fat, and Bile Acid Excretion*

\begin{tabular}{|c|c|c|c|c|c|c|c|c|}
\hline \multirow[b]{2}{*}{ Patients } & \multirow[b]{2}{*}{ Age } & \multirow[b]{2}{*}{ Sex } & \multicolumn{2}{|l|}{ Clinical features } & \multicolumn{4}{|c|}{ Daily fecal excretion } \\
\hline & & & Original diagnosis & $\begin{array}{l}\text { Extent of } \\
\text { resection } \$ \S\end{array}$ & $\begin{array}{l}\text { Frequency } \\
\text { No. }\end{array}$ & Weight & Fat & $\begin{array}{l}\text { Bile } \\
\text { acid }\end{array}$ \\
\hline \multicolumn{9}{|l|}{ Group A } \\
\hline K. R. & 28 & $\mathrm{~F}$ & Regional enteritis & 15 & 8 & 1200 & 7 & 1021 \\
\hline E. M. S. & 44 & $\mathrm{~F}$ & Regional enteritis & 13 & 10 & 880 & - & 1140 \\
\hline A. C. & 42 & $\mathrm{~F}$ & $\begin{array}{l}\text { Regional enteritis } \\
\quad \text { (partial obstruction) }\end{array}$ & 14 & 3 & 340 & 1 & 363 \\
\hline J. S. & 55 & $\mathrm{~F}$ & Regional enteritis & 12 & 11 & 740 & 3 & - \\
\hline W. S. & 61 & $\mathbf{M}$ & Pancreatic insufficiency & 0 & 3 & 889 & 45 & 574 \\
\hline A. W. & 35 & $\mathrm{~F}$ & Ileal bypass & 33 & 2 & 650 & 35 & 600 \\
\hline Mean & & & & 14 & 6 & 781 & 18 & 739 \\
\hline \multicolumn{9}{|l|}{ Group B } \\
\hline E. S. & 54 & $\mathrm{~F}$ & Regional enteritis & 82 & 5 & 2442 & 105 & 4034 \\
\hline E. W. & 71 & $\mathrm{~F}$ & Intestinal tuberculosis & 81 & 6 & 1019 & 60 & 1377 \\
\hline G. D. & 25 & $\mathrm{~F}$ & Regional enteritis & 70 & 6 & 1750 & 139 & 1956 \\
\hline F. M. & 61 & $\mathbf{M}$ & Regional enteritis & 80 & 5 & 1510 & 136 & 3300 \\
\hline C. B. & 20 & $\mathbf{M}$ & Regional enteritis & 67 & 4 & 1170 & 7 & 2100 \\
\hline Mean & & & & 76 & 5 & 1578 & 89 & 2553 \\
\hline \multicolumn{5}{|c|}{ Significance of difference $(P)$ between groups A and B } & NS & NS & $<0.05$ & $<0.01$ \\
\hline
\end{tabular}

* All figures rounded off to nearest whole integer.

¥ This figure includes small bowel resected and/or diseased.

$\S$ The proximal half of the colon had been resected in patients K. R., E. M. S., and A. W. in group A, and in patients

E. S. and F. M. in group B. In all other patients the colon was intact. 
the study period and were hospitalized in the Clinical Research Unit.

\section{Procedure}

After an overnight fast each patient was given $10 \mu \mathrm{Ci}$ cholic acid- ${ }^{14} \mathrm{C}$ by vein early in the morning. $3 \mathrm{hr}$ later, with breakfast, patients ingested $2 \mu \mathrm{Ci}{ }^{51} \mathrm{CrCl}_{s}$ in water. During the next $36-96 \mathrm{hr}$, each individual stool was collected in a separate container (paint can), frozen immediately, and kept frozen until analysis. The diet was unrestricted throughout the study.

After intravenous administration cholic acid- ${ }^{14} \mathrm{C}$ is removed from the circulation by the liver, conjugated with glycine or taurine, and excreted in bile. The physical properties of the individual conjugates and the extent of their subsequent modification (deconjugation, dehydroxylation, etc.) by bacteria in the intestinal tract will influence intestinal absorption. Since conjugation and bacterial modification were not measured, we refer in this paper to the excretion and coefficient of absorption of labeled cholic acid, rather than to the modified molecule, as it probably exists in the intestinal lumen.

\section{Materials}

Cholic acid-24- ${ }^{14} \mathrm{C}$ was obtained from Mallinkrodt Chemical Works (St. Louis, Mo.) (SA $5.37 \mathrm{mCi} / \mathrm{mmole}$ ). Distribution analysis by thin-layer chromatography (TLC) showed that $98.8 \%$ of the radioactivity migrated with an $R_{f}$ value identical with that of cholic acid, the remainder trailing. The isotope was transferred to a sterile container, dried, and heated at $80^{\circ} \mathrm{C}$ for $16 \mathrm{hr}$. It was reconstituted with $95 \%$ ethanol and sterile saline, sealed, and refrigerated until use. ${ }^{51} \mathrm{CrCl}_{3}$ was purchased from Mallinckrodt Chemical Works (SA330 $\mathrm{mCi} / \mathrm{mg}$ ), and was stated to be $99+\%$ radiochemically pure. It was diluted with tap water and refrigerated until used.

\section{Analytical methods}

${ }^{51} \mathrm{Cr}$. Stool specimens were thawed, weighed, and thoroughly homogenized by shaking with a paint can shaker. $2-g$ portions of each stool homogenate were mixed with 5 $\mathrm{ml}$ of water, and the gamma emission was measured in a well scintillation counter. A sample of the ${ }^{51} \mathrm{CrCl}_{3}$ solution administered to the patient was diluted in the same manner, and its activity was assayed at the same time. All samples were analyzed in duplicate.

Cholic acid $-{ }^{14} C$. Bile salt was extracted, and its radioactivity was assayed essentially as described previously (4). Duplicate 2-g portions of each homogenized stool were placed in $100-\mathrm{ml}$ Rockefeller hydrolysis tubes, and 40 $\mathrm{ml}$ of $2 \mathrm{~N}$ ethanolic $\mathrm{NaOH}$ was added to each sample. To one of each pair of duplicate specimens was added a known amount of cholic acid $-24-{ }^{14} \mathrm{C}$ as internal standard to calculate the efficiency of extraction. The specimens were then autoclaved at $16 \mathrm{psi}$ and $120^{\circ} \mathrm{C}$ for $90 \mathrm{~min}$. After hydrolysis, $5-10 \mathrm{ml}$ of distilled water was added to each specimen, which was then acidified to below $\mathrm{pH} 2$ with $7-10 \mathrm{ml}$ concentrated $\mathrm{HCl}$. After cooling, the acidic sterols were extracted five times with $20-\mathrm{ml}$ portions of diethyl ether. The ether extracts were combined, dried completely on a flash evaporator, and reconstituted to $5 \mathrm{ml}$ with $95 \%$ ethanol. This solution was used for radioassay and for enzymatic analysis of total bile acids. Duplicate $0.5 \mathrm{ml}$ portions were placed in counting vials with $15 \mathrm{ml}$ of Bray's solution (11), and the radioactivity was assayed in a liquid scintillation spectometer. Automatic external standard was used for quench correction. Internal standard recoveries ranged from 85 to $102 \%$ with an average of $95 \%$. No ${ }^{51} \mathrm{Cr}$ radioactivity was present.

\section{Enzymatic analysis of fecal bile acid}

Since the ethanol extract of fecal acidic sterols also contained fatty acids, it was necessary to separate the bile acids by TLC on Silica Gel G. Duplicate $0.5 \mathrm{ml}$ portions of this ethanol solution were streaked in a band on the plates and developed in hexane, diethyl ether, and glacial acetic acid $(80: 20: 1)$ (12). In this solvent system fatty acids, diand triglycerides move toward the front. Most bile acids remain at the origin; lithocholic acid migrates a few millimeters. Chemically pure bile acid (cholic, deoxycholic, chenodeoxycholic, and lithocholic) and fatty acid standards were used. Plates were sprayed with $1 \%$ iodine in methanol. After evaporation of the latter, the silica gel which contained the bile acid was scraped into a test tube, and the bile acids were extracted from the silica gel with five washes, $6-8 \mathrm{ml}$ each, of $60 \%$ ethanol which contained $2.5 \%$ glacial acetic acid. Extraction was facilitated by agitation on a Vortex shaker for $1 \mathrm{~min}$. The pooled extracts were evaporated to dryness and reconstituted with 5-10 ml $20 \%$ methanol. The $\mathrm{pH}$ of the final methanol solution was always 6-7. Bile acid concentration was then determined using 3-steroid dehydrogenase (Worthington Biochemical Corp., Freehold, N. J.) $(13,14) .100 \mathrm{mg}$ of the enzyme was homogenized with $10 \mathrm{ml}$ cold water at $1-2^{\circ} \mathrm{C}$ for 5 min and then centrifuged at $0^{\circ} \mathrm{C}$ and $28,000 \mathrm{~g}$ for $20 \mathrm{~min}$ The supernate was decanted into a cold flask and used within $24 \mathrm{hr}$ or frozen at $-20^{\circ} \mathrm{C}$. The nicotinamide-adenine dinucleotide ( $\mathrm{NAD}^{+}$, Sigma Chemical Co., St. Louis, Mo.) was diluted in distilled water at $0^{\circ} \mathrm{C}$ to a final concentration of $0.68 \mu \mathrm{mole} / 0.1 \mathrm{ml}$. The $\mathrm{pH}$ was adjusted to 7.0 with $5 \%$ sodium carbonate, and the solution was refrigerated until use (within 2-3 days). $0.1 \mathrm{M}$ pyrophosphate buffer and $3.0 \mathrm{~mm}$ hydrazine hydrate were titrated to $\mathrm{pH}$ 9.5 with $2 \mathrm{~N}$ sulfuric acid. $0.5 \mathrm{ml}$ of the bile solution, 1.1 $\mathrm{ml}$ pyrophosphate buffer, $1 \mathrm{ml}$ hydrazine hydrate, $0.1 \mathrm{ml}$ $\mathrm{NAD}^{+}$, and $0.3 \mathrm{ml}$ enzyme solution were gently stirred in a test tube and incubated for $40 \mathrm{~min}$ at room temperature. The generation of $\mathrm{NADH}$ was measured on a Beckman DU spectrophotometer at $340 \mathrm{~m} \mu$. A standard solution of bile acid was always analyzed simultaneously. The coefficient of variation of duplicate determinations of fecal bile acid was $6 \%$.

\section{Recovery of bile acid from stool}

To determine the efficiency of extraction and measurement of unlabeled fecal bile acid, a fresh fecal specimen was homogenized, and duplicate $2-\mathrm{g}$ portions were taken for analysis. A mixture of known quantities of cholic, deoxycholic, and chenodeoxycholic acids was added to the remainder which was homogenized again and incubated in a water bath at $37^{\circ} \mathrm{C}$ for half-hourly periods up to $2 \mathrm{hr}$. It was assumed that the added bile acids were metabolized by bacteria during the incubation. Bile acid mass was determined as described above. At each time period recovery was $85-104 \%$; the mean was $92 \%$.

\section{Fecal water}

An 8-10 g portion from each fecal specimen was heated in a preweighed beaker on a hot plate for $6 \mathrm{hr}$ at approximately $100^{\circ} \mathrm{C}$. Further heating did not decrease the weight. 
Fecal water was calculated as the difference between preand postheating weight. Corrections were made for those fecal specimens that required addition of water for homogenization.

\section{Calculations}

The fecal excretion of the isotopes was analyzed by two methods. In the first, the percentage of the administered dose in each individual stool was plotted against time so that the time of peak isotope excretion could be determined. In the second method, the accumulated amount of isotope excreted was subtracted from the amount administered, and the logarithm of the fraction that remained was plotted against time, as previously described (4). The ${ }^{51} \mathrm{Cr}$ and cholate- ${ }^{14} \mathrm{C}$ slopes for each set of date were calculated by the method of least squares (15). The half-lives ( $\left.t \frac{1}{2}\right)$ were determined from these estimated slopes. These slopes are subsequently referrd to as excretion constants The kinetics of the excretion of both isotopes were best described as a single exponential function. In a few patients in both groups, the data from the first one or two stools did not correspond with the slopes calculated from the remaining data, but seemed to be excreted more rapidly. When this occurred, it was always with both isotopes and was not related to stool frequency, length of small intestinal or colonic resection or fecal bile acid excretion. These early irregular data were not included in the calculations.

The absorption coefficient $(Y)$ for cholic acid was defined as follows: $Y=K_{2}-K_{1} / K_{2}$ where $K_{2}$ is the excretion constant for ${ }^{51} \mathrm{Cr}$ and $K_{1}$ is the excretion constant for cholic acid-14 $\mathrm{C}$. The significance of the differences between the two groups of patients was determined by the Wilcoxon rank sum test (16). Correlation coefficients and their significance were calculated in the usual manner (17).

\section{RESULTS}

Isotope excretion. The rate of ${ }^{51} \mathrm{CrCl}_{8}$ excretion varied widely (Table II, Fig. 1). It was not related to length of resection, daily fecal mass, daily fecal fat, or fecal frequency. Patient J. S. (group A) who had severe watery diarrhea and minimal ileal disease, had the most rapid rate of excretion ( $t \frac{1}{2}=0.08$ days, $<2 \mathrm{hr}$ ) whereas patient $K . R$. (group A) with a distal ileal resection had the slowest ( $t_{\frac{1}{2}}=0.42$ days). The $t_{\frac{1}{2}}$ of ${ }^{51} \mathrm{Cr}$ was similar in the two groups with a range of $0.08-1.67$ days in patients from group $\mathrm{A}$, and $0.33-1.28$ days in those from group B.

The peak excretion of ${ }^{51} \mathrm{Cr}$ occurred earlier in group $B$ patients. The mean peak of ${ }^{51} \mathrm{CrCl}_{3}$ excretion in group $A$ was 0.68 days, and in group $B$ it was 0.16 days, but the difference was not statistically significant. In several patients in both groups, there was a second ${ }^{51} \mathrm{CrCl}_{3}$ excretion peak occurring from 6 to $17 \mathrm{hr}$ after the first excretion peak (Fig. 2). The exact explanation for the second peak is not clear. It was probably caused by storage of the isotope in the colon although the extent of colectomy did not correlate well with the size or presence of the second peak.

Cholic acid-24- ${ }^{14} \mathrm{C}$. The $\mathrm{t}_{\frac{1}{2}}$ of isotopic cholic acid ranged from 0.65 to 8.4 days in group $A$ patients and 0.13 to 1.45 days in group $B$ patients (Table II, Fig. 1) $(P<0.05)$. Patient A. C. (group A), who had partial

TABLE JI

Isotope Excretion Data

\begin{tabular}{|c|c|c|c|c|c|c|c|}
\hline \multirow[b]{2}{*}{ Patients } & \multicolumn{3}{|c|}{${ }^{51} \mathrm{CrCl}_{3}$} & \multicolumn{3}{|c|}{ Cholic acid ${ }^{14} \mathrm{C}$} & \multirow{2}{*}{$\begin{array}{l}\text { Cholic acid } \\
\text { absorption } \\
\text { coefficient } \\
(Y)\end{array}$} \\
\hline & $t_{\frac{1}{2}}$ & $\begin{array}{l}\text { Excretion } \\
\text { constant } \\
\left(K_{2}\right)\end{array}$ & $\begin{array}{c}\text { Peak } \\
\text { excretion }\end{array}$ & $t_{\frac{1}{2}}$ & $\begin{array}{l}\text { Excretion } \\
\text { constant } \\
\left(K_{1}\right)\end{array}$ & $\begin{array}{l}\text { Peak } \\
\text { excretion }\end{array}$ & \\
\hline & days & $\operatorname{days}^{-1}$ & days & days & $d a y s^{-1}$ & $d a y s$ & \\
\hline \multicolumn{8}{|l|}{ Group A } \\
\hline K. R. & 1.67 & 0.42 & 0.10 & 4.6 & 0.15 & 0.10 & 0.64 \\
\hline E. M. S. & 0.14 & 4.90 & 0.27 & 0.65 & 1.07 & 0.38 & 0.78 \\
\hline A. C. & 1.25 & 0.55 & 1.13 & 8.4 & 0.08 & 1.13 & 0.80 \\
\hline J.S. & 0.08 & 8.66 & 0.27 & 1.55 & 0.45 & 0.27 & 0.95 \\
\hline W. S. & 0.21 & 3.33 & 1.08 & 3.2 & 0.22 & 1.88 & 0.93 \\
\hline A. $\mathbf{W}$. & 0.79 & 0.88 & 1.25 & 1.96 & 0.36 & 1.25 & 0.55 \\
\hline Mean & 0.69 & 3.12 & 0.68 & 3.39 & 0.39 & 0.83 & 0.78 \\
\hline \multicolumn{8}{|l|}{ Group B } \\
\hline E. S. & 0.12 & 5.70 & 0.19 & 0.13 & 5.20 & 0.04 & 0.09 \\
\hline E. W. & 1.28 & 0.54 & 0.06 & 1.45 & 0.48 & 0.06 & 0.12 \\
\hline G. D. & 0.54 & 1.28 & 0.04 & 0.52 & 1.33 & 0.04 & 0.00 \\
\hline F. M. & 0.89 & 0.77 & 0.19 & 0.89 & 0.77 & 0.10 & 0.00 \\
\hline C. B. & 0.33 & 0.42 & 0.33 & 0.43 & 1.60 & 0.33 & 0.24 \\
\hline Mean & 0.63 & 1.74 & 0.16 & 0.68 & 1.88 & 0.12 & 0.09 \\
\hline $\begin{array}{l}\text { Significance of difference } \\
\text { between groups } A \text { and } B\end{array}$ & NS & NS & NS & $<0.05$ & $<0.05$ & $<0.05$ & $<0.01$ \\
\hline
\end{tabular}


ileal obstruction due to regional enteritis and no intestinal resection at the time of study, had the longest cholic acid half-life (8.4 days). Patient E. S. (group B) who had an $83 \%$ intestinal resection and a jejunotransverse colostomy had the shortest cholic acid t $\frac{1}{2}$ ( 0.13 days, slightly more than $3 \mathrm{hr}$ ). Although the excretion rates differed in the two groups of patients, it did not significantly correlate with the length of intestinal resection in individual patients $(r=0.47, P>0.05)$. The rate of labeled cholic acid excretion was not significantly correlated with fecal fat or fecal frequency, but was highly related to the daily fecal mass $(r=0.83 P<0.01)$.

The relation between the rates of excretion of the two isotopes is quite different in the two groups of patients (Fig. 3). In those with extensive ileal resection or disease, the isotopes were excreted at almost identical rates, while in those with less ileal destruction ${ }^{51} \mathrm{Cr}$ was excreted more rapidly than cholate- ${ }^{14} \mathrm{C}$.

The mean time of the peak excretion of labeled cholic acid ranged from 0.10 to 1.88 days in group $\mathrm{A}$ and from 0.04 to 0.33 days in group B (Table II) $(P<0.01)$. In several patients, a second peak for cholic acid excretion occurred from 6 to $19 \mathrm{hr}$ after the first. This second peak was present only when there was also a second peak of ${ }^{51} \mathrm{CrCl}_{3}$ excretion. In group $\mathrm{B}$ patients, the percentage of each isotope in each stool was frequently identical (Figs. 2 and 3).

Coefficient of cholic acid absorption. The cholic acid absorption coefficient $(Y)$ ranged from 0.55 to 0.95 (mean 0.78 ) in group $A$ and from zero to 0.24 (mean 0.09 ) in group B (Table II); it was inversely related to the length of intestine resected or diseased (Fig. 4). The $Y$ value was zero in two patients in group $\mathrm{B}$, indicating no cholic acid absorption. Duodenal juice obtained from one of these patients (at another time) contained no deoxycholic acid, consistent with the conclusion that there was no enterohepatic circulation of bile acid (or that there was no bacterial dehydroxylation of cholic acid). The cholic acid absorption coefficient was inversely related to daily fecal bile acid excretion $(r=$ $-0.81, P<0.01$ ), but did not significantly correlate with transit time, fecal fat, or fecal frequency.

Fecal mass and bile acid. The daily fecal mass was increased in all patients (Table I). The mean was 770 $\mathrm{g}$ in group $\mathrm{A}$ and $1578 \mathrm{~g}$ in group $\mathrm{B}$; the difference between the groups was not statistically significant. Increased fecal mass was due mainly to an excess of fecal water. Water constitutes $75-80 \%$ of normal fecal weight but in both patient groups, fecal water accounted for $90-97 \%$ of the fecal mass. Individual fecal weights varied considerably in patients from both groups. The mean individual stool weight was $228 \mathrm{~g}$ (range 113-324 g) in patients from group $\mathrm{A}$ and $356 \mathrm{~g}$ (range 146-487) in those from group $B$.

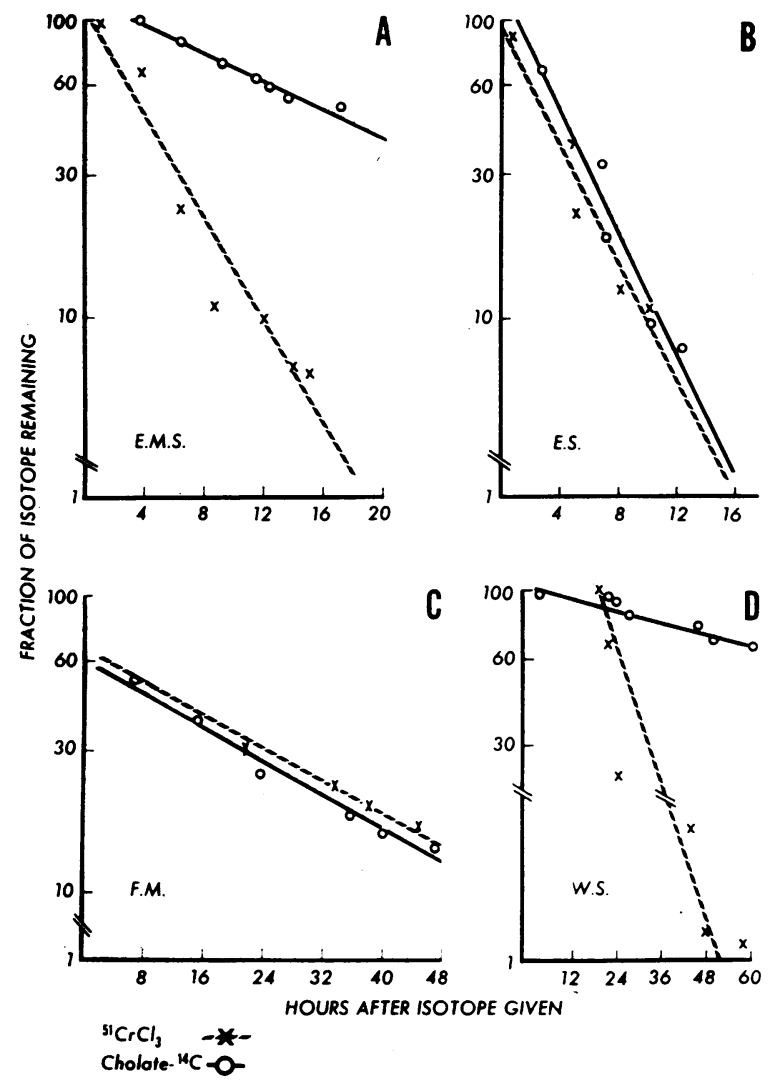

FIGURE 1 The fraction of the isotopes remaining in the body after the intravenous administration of cholic acid${ }^{14} \mathrm{C}$ and the oral administration of ${ }^{5} \mathrm{CrCl}_{3}$ in each of four patients. Each point represents an individual fecal specimen. The lines are calculated regression lines. (A) Patient E. M. S., group $\mathrm{A}$, had rapid excretion of ${ }^{51} \mathrm{CrCl}_{3}$ and a somewhat slower excretion rate of cholate- ${ }^{14} \mathrm{C}$ indicating reabsorption of cholate- ${ }^{14} \mathrm{C}$. Coefficient of absorption $(Y)$ was 0.78. (B) Patient E. S., group $B$, with a massive small bowel resection $(82 \%)$, excreted both isotopes rapidly and at identical rates. There was no absorption and no enterohepatic circulation of radioactive cholic acid. (C) Patient F. M., group B, had $80 \%$ of his small intestine resected. The isotopes were excreted in an identical manner. There was no absorption of labeled cholic acid. (D) W. S., a $61 \mathrm{yr}$ old man with pancreatic insufficiency and a normal small intestine, had a fairly rapid excretion of ${ }^{51} \mathrm{Cr}\left(\mathrm{t}_{2} \frac{1}{2}\right.$, 0.21 days), but a much slower excretion of cholic acid- ${ }^{14} \mathrm{C}$ ( $t \frac{1}{2}, 3.2$ days). Neither isotope appeared in stool in appreciable quantities during the first $24 \mathrm{hr}$. The coefficient of cholic acid absorption was 0.93 .

Fecal bile acid excretion ranged from 363 to $1140 \mathrm{mg} /$ day in group A and from 1377 to $4034 \mathrm{mg} /$ day in group B $(P<0.01)$ (Table I) and was directly related to the length of small intestine resected or diseased. The mass of bile acid present in each stool specimen varied from 128 to $230 \mathrm{mg}$ (mean $166 \mathrm{mg}$ ) in group A patients and from 313 to $717 \mathrm{mg}$ (mean $546 \mathrm{mg}$ ) in group B patients. 

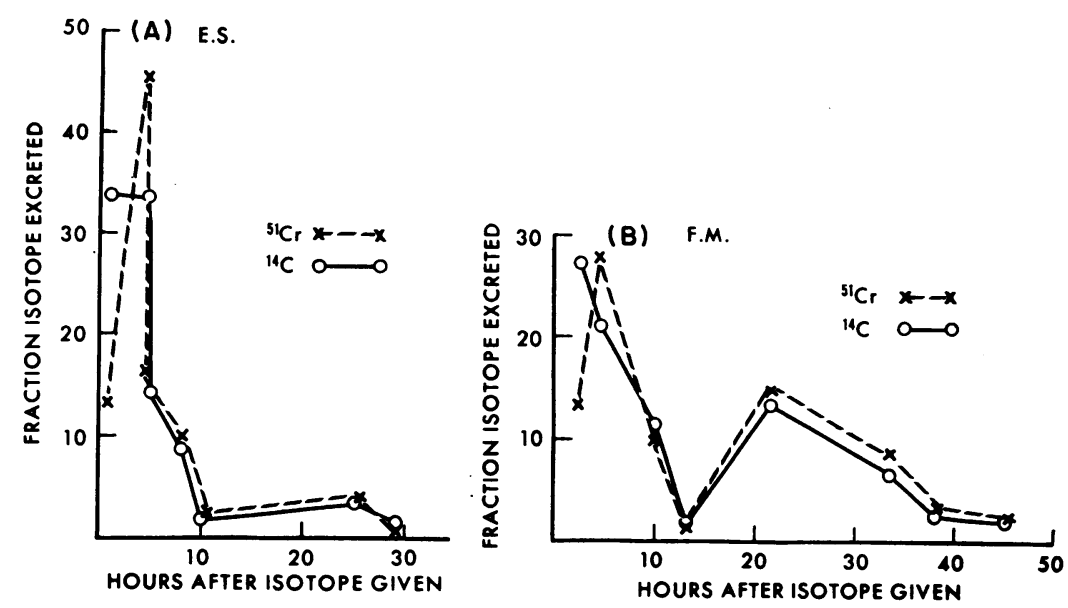

FIGURE 2 The fraction of each isotope that was recovered in each individual stool specimen is plotted against time. In patient E. S. (A) whose proximal colon had been resected, there was only one peak of excretion and in patient F. M. (B) whose right colon was almost entirely intact, there were two peaks. In these two patients with massive intestinal resection, both isotopes were excreted in an identical manner.

The bile acid mass in individual stool specimens did not vary with meals in a recognizable manner.

Daily fecal bile acid excretion was directly related to daily fecal mass $(r=0.86, P<0.01$ ) (Fig. 5). For each $100 \mathrm{mg}$ increase in fecal bile acid, fecal mass increased by approximately $60 \mathrm{~g}$. Furthermore, in each individual stool specimen the bile acid mass was also directly related to fecal mass (Figs. 6 and 7 ). This relationship was statistically significant at the 0.01 level for eight patients and at the 0.05 level for the ninth patient with ileal disease or resection. It was not a statis-

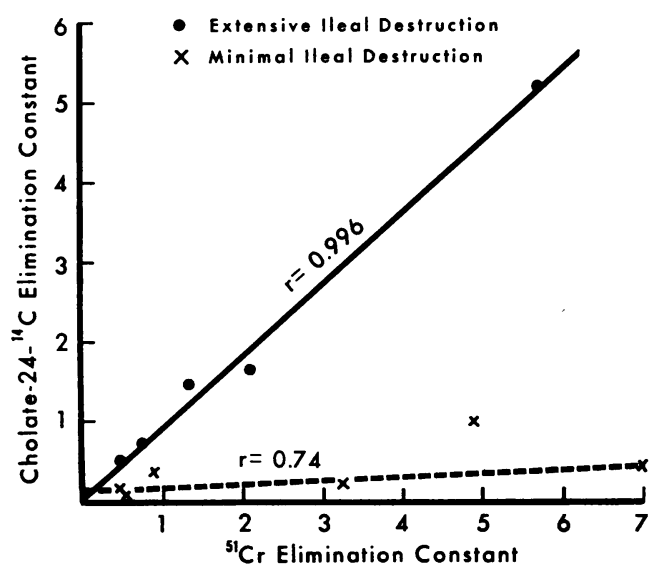

Figure 3 The cholic acid-14 $\mathrm{C}$ excretion constant and the ${ }^{51} \mathrm{Cr}$ excretion constant for each patient are plotted against each other. The two groups of patients are clearly separated. In the patients with extensive ileal resection or disease, group $\mathrm{B}$, the similarity of excretion constants is apparent $(P<0.001)$. tically significant relationship for W. S., the patient with pancreatic insufficiency and a normal ileum. The ratio of fecal bile acid to fecal mass was slightly different for each patient. As anticipated, fecal bile acid excretion showed a similar relationship to fecal water excretion $(P<0.01)$ (Fig. 8). For each millimole increase in fecal bile acid excretion, fecal water excretion increased by approximately 11 moles. Fecal bile acid, fecal mass, and fecal water were not related to fecal fat or the frequency of stools.

\section{DISCUSSION}

Although a small amount of bile salt is passively absorbed from both jejunum (18) and the colon (19), the enterohepatic circulation of bile salts is primarily dependent upon active absorption from the ileum (20-22). Abnormally rapid fecal elimination of intravenously or orally administered isotopic cholic acid has been demonstrated in laboratory animals after ileal resection or bypass (23) and in man with ileal resection, bypass, or disease (3-5). These observations were confirmed and extended in the present study, which showed an excellent correlation between length of ileum diseased or resected and bile salt malabsorption.

Heretofore, bile acid kinetics have not been studied accurately in short bowel patients because techniques were not appropriate. We developed a new technique for studying bile acid kinetics that is applicable in short bowel patients, and indeed, in any patient with diarrhea.

In 1967, Hofmann proposed a model of the enterohepatic circulation of bile salts that made possible the calculation of either the fractional absorption of a bile 


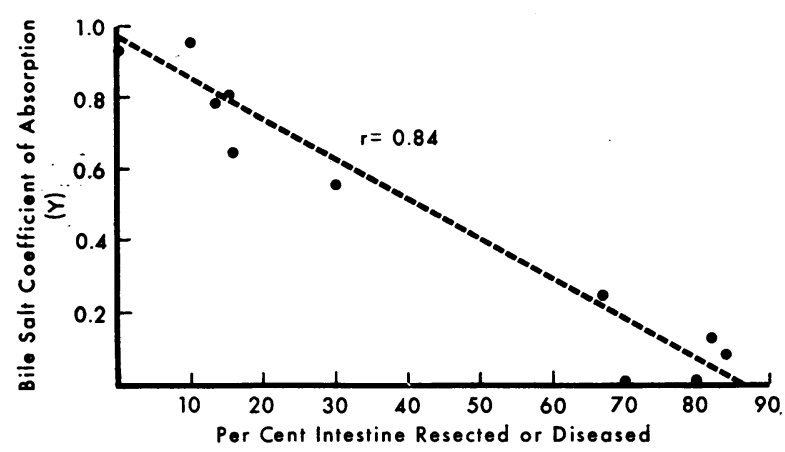

FIGURE 4 The effect of intestinal resection or disease on the absorption efficiency of cholic acid $(Y)$. The regression line is hatched because the number of observations is small and may not represent a true linear relationship. As the length of intestine diseased or resected progressively increases, the absorption of cholic acid decreases $(P<0.01)$. Two of the patients had no cholic acid absorption.

salt or its daily synthesis rate, assuming that one or the other was known. The model as well as Stanley's (24) assumes that in the steady-state fecal excretion is equal to hepatic synthesis of bile salt and that the bile salt undergoes a definite number of enterohepatic cycles per day. In patients with a massive intestinal resection, these concepts are not useful for two reasons. Firstly, bile salt is excreted very rapidly so that essentially the entire bolus discharged from the gallbladder is frequently lost within a few hours (25). Under these circumstances the bile salt pool is not reasonably constant throughout the day, a condition necessary for Hofmann's model to be valid (1). Secondly, since there is little or no enterohepatic circulation of bile salt, there can be no finite number of enterohepatic cycles per day. In patients with only partial interruption of the enterohepatic circulation, these objections are less serious, but the extent to which they invalidate the model in any patient cannot be determined accurately.

The two features of our new technique which made it possible to determine accurately cholic acid excretion rate and the coefficient of its absorption are the measurement of labeled bile acid in each individual stool specimen and the simultaneous measurement of the excretion of a nonabsorbable marker.

In earlier studies, $24-\mathrm{hr}$ fecal specimens were employed for the determination of isotopic cholic acid elimination rate, but since patients with extensive ileal disease or resection excrete $50-95 \%$ of labeled cholic acid within $24 \mathrm{hr}$ the precision of data analysis is necessarily limited. More exact determination of bile acid excretion rate is made possible by the measurement of labeled bile acid in each stool specimen. Stanley and Nemchausky, who used individual stool analyses to determine isotopic cholic acid excretion, found a mean $t_{\frac{1}{2}}$ of 1.06 days in four patients with ileal disease or resection (5).

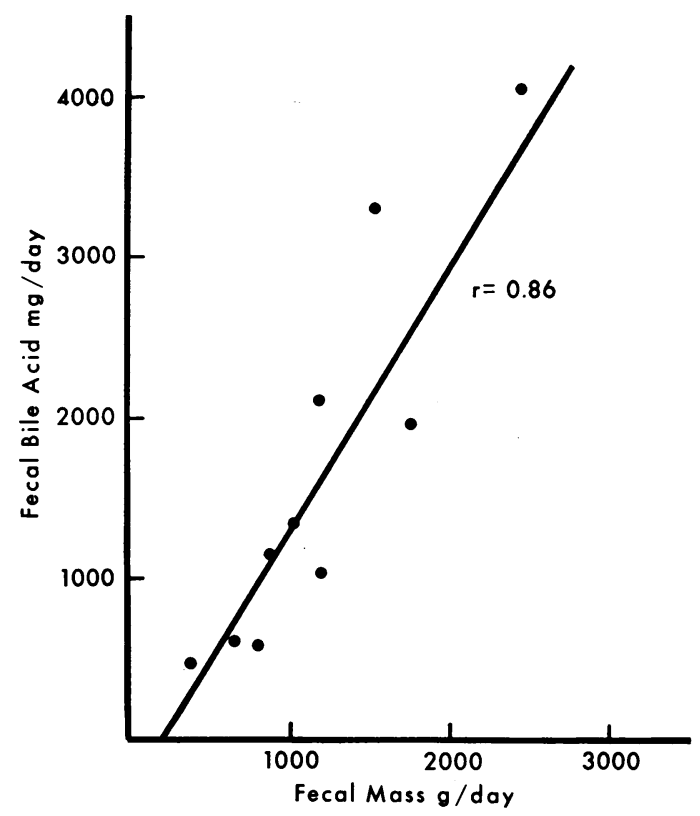

FIGURE 5 The relationship between daily fecal mass and bile acid. A direct linear relationship is seen. For each 100 $\mathrm{mg}$ increase in fecal bile acid, fecal mass increases approximately $60 \mathrm{~g}$.

In our study, the elimination rate of cholic acid increased with the extent of ileal disease or resection; it clearly separated patients with a small resection from those who had large resections. The mean $\frac{1}{2}$ in the latter was 3.39 days and in the former it was 0.68 days.

A nonabsorbable fecal marker has not been used

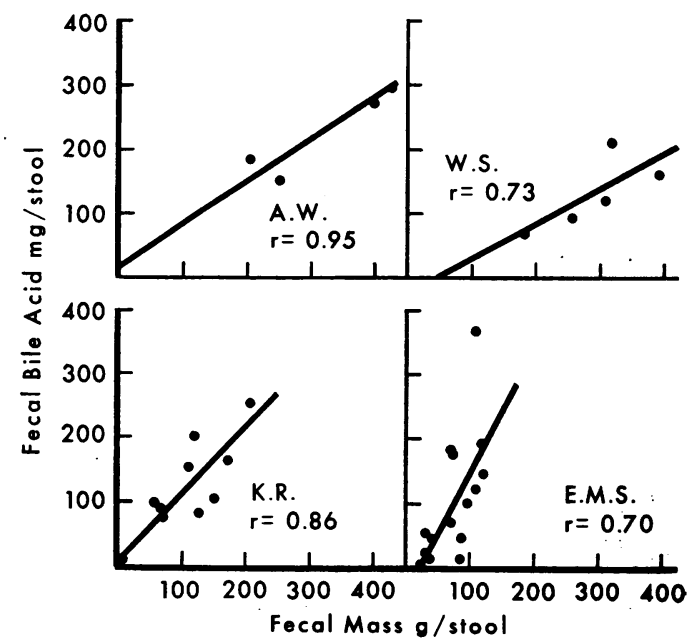

Figure 6 The relationship between fecal mass and fecal bile acid in each individual stool in group A patients. For each patient there is a distinctive and direct, linear correlation between the mass of each stool and its bile acid content. The correlation was statistically significant for every patient except W. S. 


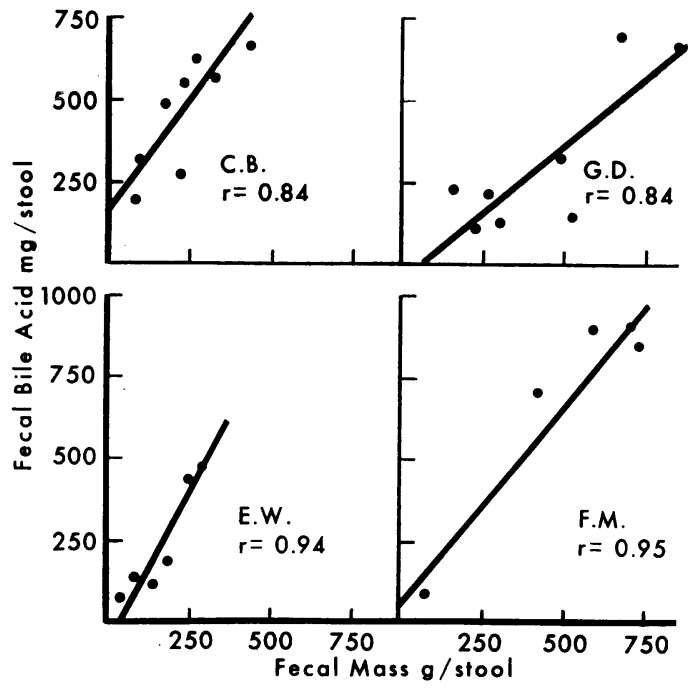

Figure 7 The relationship between fecal mass and fecal bile acid in each individual stool in group B patients. Again for each patient there is a direct linear correlation between the mass of each stool and its bile acid content, which is statistically significant for every patient.

previously to help measure the efficiency of absorption of bile acid. We selected ${ }^{51} \mathrm{CrCl}_{3}$ as a marker because it is neither absorbed nor metabolized. Donaldson and Barreras recovered in the feces $99.6 \%$ of a tracer dose of ${ }^{51} \mathrm{CrCl}_{3}$ given orally to normal subjects (26). It is easily measured in feces and can be completely separated from radioactive bile salt. Both groups of patients excreted the ${ }^{{ }^{51}} \mathrm{CrCl}_{3}$ rapidly, but the rate of its excretion varied widely and did not clearly separate the two groups of patients. The peak excretion was much earlier for group B patients, as anticipated, but again, the two groups were not separated by statistically significant differences.

${ }^{51} \mathrm{CrCl}_{3}$ appears to be a valid marker for this purpose. In order to be valid, the two isotopes must be well mixed in the proximal small intestine. The manner and time of their administration were planned to assure such mixing. The radioactive cholic acid was given by vein, and several hours later, when it was stored in the gallbladder of the fasting patient (27), the ${ }^{51} \mathrm{CrCl}_{3}$ was given with breakfast. It is recognized that thorough mixing in the intestinal tract is dependent upon the rate of gastric emptying and the rate of evacuation of the biliary tract. Since these processes may, on occasion, vary unpredictably, the isotopes may not always be well mixed. In the patients studied, however, this problem did not appear to be significant. Although duodenal concentrations were not determined, simultaneous excretion of the same proportion of both isotopes in several patients (Fig. 2) strongly supports the assumption that they were well mixed. Since they were mixed in the duodenum, the difference in excretion rates is due solely to absorption of the labeled cholic acid. The fractional absorption of cholic acid can then be calculated from the difference in the excretion rates of the two isotopes.

The coefficient of cholic acid absorption $(Y)$, determined by this method, correlated well with other findings and clearly separated the two groups of patients. Group A patients (with small resection) had normal or moderately decreased coefficients of cholic acid absorption, whereas group B patients (with large resections) had markedly decreased or even zero coefficients of cholic acid absorption. The coefficient of cholic acid absorption was normal (0.93) in the patient (W. S.) with diarrhea and fat malabsorption due only to pancreatic insufficiency.

Some patients in both groups excreted each isotope in a single peak, while other patients excreted each isotope in a double peak. Since the excretion characteristics of both isotopes were always the same in a given patient, it is most likely that excretion in a single or double peak reflected flow characteristics in the intestinal lumen and not enterohepatic circulation of bile acid. The extent of colectomy, however, was not related to these excretion patterns. The presence of a gallbladder might affect the excretion characteristics of labeled cholic acid by patients with ileal disorders, but since only two of our patients had had a cholecystectomy, it was not possible to attribute an effect to the gallbladder.

In these studies of radioactive bile acid excretion, only cholic acid was studied. It is not known whether the magnitude of chenodeoxycholic acid malabsorption is the same as that of cholic acid malabsorption in patients with ileal resection. Wollenwebber, Kottke, and Owen found that chenodeoxycholic acid had a slightly longer half-life and smaller turnover rate than cholic acid in six hypercholesterolemic patients (28). Conversely,

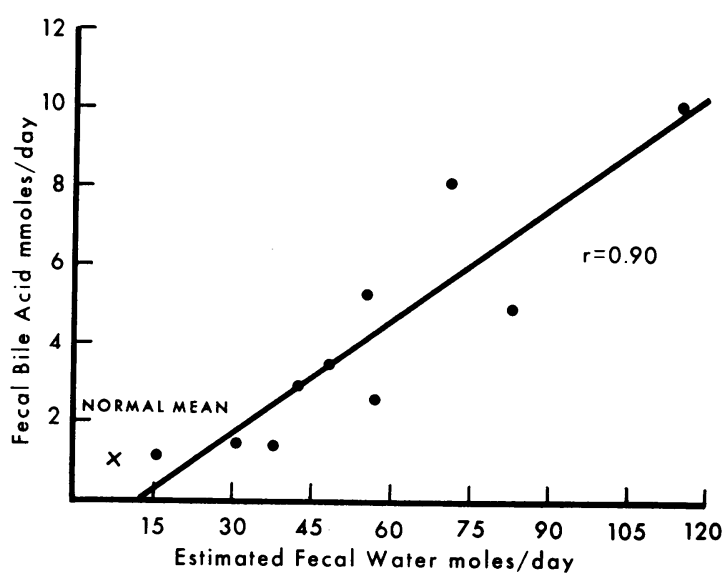

FIGURE 8 The relationship between fecal water in moles/ day and fecal bile acid in millimoles/day. For each millimole increase in fecal bile acid, fecal water increases by approximately 11 moles. The " $x$ " represents the calculated normal mean. 
nearly identical turnover rates have been described for hoth bile acids in the rat (29). Hislop, Hofmann, and Schoenfield reported more jejunal absorption of chenodeoxycholic than of cholic acid (30). Further investigation of chenodeoxycholic metabolism is needed.

The direct and close relationship between fecal bile acid and fecal water for each $24 \mathrm{hr}$ period and in each individual fecal specimen is an important finding. Normal human feces contain approximately $77 \%$ water, and the total daily mass is $100-200 \mathrm{~g}$ (31). Fecal mass was abnormal in all of the patients studied, and water content was $90-97 \%$ with a mean of $92 \%$. Thus, most of the fecal weight was water. Devroede and Phillips, who perfused the normal human colon in 15 subjects with isotonic electrolyte solutions, showed that colonic water transport is dependent upon colonic sodium transport, i.e., with net sodium absorption there was net water absorption and with no sodium absorption there was no water absorption (32). Mekhjian and Phillips perfused canine colons with electrolyte and $10 \mathrm{~mm}$ bile acid solutions and found that deoxycholic acid and, to a lesser extent, chenodeoxycholic acid, but not cholic acid, produced significant reductions in net absorption of sodium chloride, bicarbonate, and water (33). Fordtran and Locklear estimated that in normal man, approximately $2 \mathrm{~mm}$ bile salt passes through the lower ileum and into the cecum (34). The normal fecal bile acid concentration of approximately $9 \mathrm{mmoles} / \mathrm{liter}$ of total fecal water indicates the efficiency of water absorption from the colon. In light of the studies of Phillips and associates $(32,33)$ the linear relationship between the fecal output of bile acid and of water is consistent with the view that malabsorption of bile acids by the ileum altered colonic water absorption in the patients studied. Our data show that for each millimole increase in fecal bile acid, fecal water is increased by approximately 11 moles.

Another important finding is the apparent increase in synthesis of bile acid. Since these patients were in the steady state, daily bile acid synthesis can be assumed to have been equal to bile acid excretion. The amount of bile acid excreted was similar to the $2.8 \pm 0.9 \mathrm{~g} /$ day reported by Hofmann and Poley (35) in nine patients with ileal resection and the $1.4-3.1 \mathrm{~g} /$ day reported by Moore, Frantz, and Buchwald in six hypercholesterolemic patients who had undergone ileal bypass (36). In the present study, the magnitude of fecal bile acid excretion and persumably synthesis was directly related to the length of ileum removed. The rates of synthesis in group B patients were 3-8 times normal, approaching the maximum of a 10 fold increase seen in monkeys after complete interruption of the enterohepatic circulation (37).

The direct relevance of this fecal bile acid-water relationship to the diarrhea of short bowel patients is not entirely clear. Hofmann and Poley reported that the watery diarrhea of patients with less than $100 \mathrm{~cm}$ of ileum resected could be very satisfactorily controlled by cholestyramine, a resin that binds bile salt and removes it from the solution in the intestinal lumen (7). In patients with larger resection, cholestyramine was not effective. These observations, which have been confirmed in our laboratory, were interpreted as showing that bile acids play an important role only in the diarrhea associated with a small ileal resection.

Bile acids are not the only determinant of fecal water excretion. For example, hydroxy fatty acids, produced by intestinal bacteria from unabsorbed fatty acids entering the colon in high concentration have been associated with diarrhea $(38,39)$. It is also quite possible that fecal water and bile acid increase pari passu, primarily because of the loss of intestinal surface area.

In general, patients who excreted large amounts of bile acid had considerable steatorrhea. However, there was not a statistically significant correlation between bile acid and fat excretion, probably because of the many other factors involved in fat malabsorption.

\section{ACKNOWLEDGMENTS}

The authors gratefully acknowledge the expert technical assistance of Miss Patricia Coan.

The work was supported by National Institutes of Health Research Grant AM 12626, National Institutes of Health Training Grant in Gastroenterology AM 05122, and by Grant FR 00051 from the General Clinical Research Centers Program of the Division of Research Resources, National Institutes of Health.

\section{REFERENCES}

1. Hofmann, A. F. 1967. The syndrome of ileal disease and the broken enterohepatic circulation: cholerheic enteropathy. Gastroenterology. 52: 752.

2. Mekhjian, H. S., S. F. Phillips, and A. F. Hofmann. 1968. Conjugated bile salts block water and electrolyte transport by the human colon. Gastroenterology. 54: 1256.

3. Austad, W. I., L. Lack, and M. P. Tyor. 1967. Importance of bile acids and of an intact distal small intestine for fat absorption. Gastroenterology. 52: 638 .

4. Meihoff, W. E., and F. Kern, Jr. 1968. Bile salt malabsorption in regional ileitis, ileal resection, and mannitol-induced diarrhea. J. Clin. Invest. 47: 261.

5. Stanley, M. M., and B. Nemchausky. 1967. Fecal $C^{14}-$ bile acid excretion in normal subjects and patients with steroid-wasting syndromes secondary to ileal dysfunction. J. Lab. Clin. Med. 70: 627.

6. Heaton, K. W., W. I. Austad, L. Lack, and M. P. Tyor. 1968. Enterohepatic circulation of $\mathrm{C}^{14}$-labeled bile salts in disorders of the distal small bowel. Gastroenterology. $55: 5$.

7. Hofmann, A. F., and J. R. Poley. 1969. Cholestyramine treatment of diarrhea associated with ileal resection. N. Engl. J. Med. 281: 397.

8. Van Deest, B. W., J. S. Fordtran, S. G. Morawski, 
and J. D. Wilson. 1968. Bile salt and micellar fat concentration in proximal small bowel contents of ileectomy patients. J. Clin. Invest. 47: 1314.

9. Bergström, S. 1961. Metabolism of bile acids. Fed. Proc. 20: 121 .

10. Haubrich, W. S. 1964. Anatomy of the small intestine. In Gastroenterology. H. L. Bockus, editor, W. B. Saunders Company, Philadelphia. 2nd edition. 2: 6.

11. Bray, G. A. 1960. A simple efficient liquid scintillator for counting aqueous solutions in a liquid scintillation counter. Anal. Biochem. 1: 279.

12. Gordon, S. G., F. Philippon, K. S. Borgen, and F. Kern, Jr. 1970. Formation of fatty acid ethyl esters during lipid extraction and storage: an important artifact. Biochim. Biophys. Acta. 218: 366.

13. Iwata, T., and K. Yamasaki. 1964. Enzymatic determination and thin-layer chromatography of bile acids in blood. J. Biochem. (Tokyo). 56: 424.

14. Palmer, R. H. 1969. The enzymatic assay of bile acids and related $3 \alpha$-hydroxy-steroids; its application to serum and other biological fluids. Methods Enzymol. 15: 280.

15. Dixon, W. J., and F. J. Massey, Jr. 1957. Introduction to Statistical Analysis. McGraw-Hill Book Company, New York. 2nd edition.

16. Bliss, C. I. 1967. Nonparometric test for comparing two samples. In Statistics in Biology; Statistical Methods for Research in the Natural Sciences. McGraw-Hill Book Company, New York. 1: 225.

17. Goldstein, A. 1964. Biostatistics, An Introductory Text. The Macmillan Company, New York. 129.

18. Dietschy, J. M. 1968. Mechanisms for the intestinal absorption of bile acids. J. Lipid Res. 9: 297.

19. Samuel, P., G. M. Saypol, E. Meilman, E. H. Mosbach, and M. Chafizadeh 1968. Absorption of bile acids from the large bowel in man. J Clin. Invest. 4: 2070.

20. Weiner, I. M., and L. Lack. 1962. Absorption of bile salts from the small intestine in vivo. Amer. J. Physiol. 202: 155 .

21. Lack, L., and I. M. Weiner. 1961. In vitro absorption of bile salts by small intestine of rats and guinea pigs. Amer. J. Physiol. 200: 313.

22. Borgstrom, B., G. Lundh, and A. Hofmann. 1963. The site of absorption of conjugated bile salts in man. Gastroenterology. $45: 229$.

23. Playoust, M. R., L. Lack, and I. M. Weiner. 1965. Effect of intestinal resection on bile salt absorption in dogs. Amer. J. Physiol. 208: 363.

24. Stanley, M. M. 1969. Steroid-wasting enteropathy: clinical picture bile salt absorption and fecal excretion, and therapy. In Conference on Bile Salt Metabolism, University of Cincinnati Medical Center, 1967. L. Schiff, J. B. Carey, Jr., and J. Dietschy, editors. Charles C. Thomas, Publisher, Springfield, Ill. 266.
25. Low-Beer, T. S., L. Lack, and M. P. Tyor. 1969. Effect of one meal on enterohepatic circulation of bile salts. Gastroenterology. 56: 1179.

26. Donaldson, R. M., Jr., and R. F. Barreras. 1966. Intestinal absorption of trace quantities of chromium. $J$. Lab. Clin. Med. 68: 484.

27. Abaurre, R., S. G. Gordon, J. G. Mann, and F. Kern, Jr. 1969. Fasting bile salt pool size and composition after ileal resection. Gastroenterology. 57: 679.

28. Wollenweber, J., B. A. Kottke, and C. A. Owen, Jr. 1967. Pool size and turnover of bile acids in six hypercholesteremic patients with and without administration of nicotinic acid. J. Lab. Clin. Med. 69: 584.

29. Lindstedt, S., and A. Norman. 1955. On the excretion of bile acid derivatives in feces of rats fed cholic acid-24- ${ }^{14} \mathrm{C}$ and chenodesoxycholic acid- $24-{ }^{14} \mathrm{C}$. Bile acids and steroids 19. Acta Physiol. Scand. 34: 1.

30. Hislop, I. G., A. F. Hofmann, and L. J. Schoenfield. 1967. Determinants of the rate and site of bile acid absorption in man. J. Clin. Invest. 46: 1070.

31. P. L. Altman and D. S. Dittmer, editors. Biological Handbooks. Metabolism. 1968. Federation of American Societies for Experimental Biology, Bethesda, Md. 515.

32. Devroede, G. J., and S. F. Phillips. 1969. Conservation of sodium, chloride, and water by the human colon. Gastroenterology 56: 101.

33. Mekhjian, H. S., and S. F. Phillips. 1970. Perfusion of the canine colon with unconjugated bile acids. Effect on water and electrolyte transport, morphology, and bile acid absorption. Gastroenterology. 59: 120.

34. Fordtran, J. S., and T. W. Locklear. 1966. Ionic constituents and osmolality of gastric and small-intestinal fluids after eating. Amer. J. Dig. Dis. 11: 503.

35. Hofmann, A. F., and J. R. Poley. 1969. Cholestyramine treatment of diarrhea associated with ileal resection: factors influencing response. Gastroenterology. 56: 1168.

36. Moore, R. B., I. D. Frantz, Jr., and H. Buchwald. 1969. Changes in cholesterol pool size, turnover rate, and fecal bile acid and sterol excretion after partial ileal bypass in hypercholesteremic patients. Surgery. 65: 98.

37. Dowling, R. H., E. E. Mack, and D. M. Small. 1970. Effects of controlled interruption of the enterohepatic circulation of bile salts by biliary diversion and by ileal resection on bile salt secretion, synthesis, and pool size in the rhesus monkey. J. Clin. Invest. 49: 232.

38. Kellock, T. D., J. R. Pearson, R. I. Russell, J. G. Walker, and H. S. Wiggins. 1969. The incidence and clinical significance of faecal hydroxy fatty acids. Gut. 10: 1055 .

39. Hofmann, A. F., J. R. Poley, H. S. Mekhjian, and S. F. Phillips. 1970. Hydroxy fatty acid: an apparent cause of diarrhea in patients with ileal resection and steatorrhea. J. Clin. Invest. 49: 44a. (Abstr.) 